\title{
THE SURVEY OF THE SAN FRANCESCO BRIDGE BY SANTIAGO CALATRAVA IN COSENZA, ITALY
}

\author{
Serena Artese ${ }^{1, *}$ \\ ${ }^{1}$ Department of Civil Engineering, University of Calabria, Cubo 45/B, Via Pietro Bucci, 87036 Rende (CS), Italy, \\ serena.artese@unical.it
}

Commission II

KEY WORDS: Laser scanner, Line scanner, Structure monitoring, Deformation, Dynamic measurements

\begin{abstract}
:
The paper deals with two kinds of surveying carried out by using the Terrestrial Laser Scanner (TLS). The object of the surveys is the new San Francesco Bridge of Santiago Calatrava in Cosenza, Italy. The classic technique has been used to obtain the 3D model of the bridge and of the surrounding environment. A second measurement has been carried out in line scanner mode, during a load test, in order to obtain the deformation of the bridge pylon during the loading phase. This methodology allows obtaining the instantaneous elastic line of the surveyed structure.
\end{abstract}

\section{INTRODUCTION}

For the surveying of the bridges, TLS is by now a consolidated technique. To perform such a survey in an optimal manner, several operational features should be taken into account ( $\hat{C}$ apo et al., 2011; Deruyter et al., 2009; Lerma et al., 2008; Tang and Akinci, 2011). A fundamental aspect is the choice of the number of scans necessary for the complete visibility of all parts of the object to be surveyed, and the station points. The peculiarity of TLS allows to obtain data both for medium-size objects and buildings or infrastructures (Artese, 2014; Artese et al., 2013a, 2016a).

The surveying of bridges is often performed by using multisource data; so TLS is integrated with punctual sensors devoted to structural monitoring (Artese et al., 2015a, 2018; Zinno et al., 2019), while geomatics techniques and remote sensing are used to monitor also the surrounding environment (Artese et al., 2015b, 2016b).

In recent times there has been a considerable increase in the use of geomatics techniques for structural monitoring, even in the dynamic phase. The sampling rate of total stations, laser scanners and high definition cameras, allows to describe the evolution of the deformations of the structures, so that these techniques are increasingly being combined with the use of traditional sensors.

In this paper, the use of TLS for the surveying of a bridge and its surrounding environment is described, along with dynamical acquisitions, performed during a load test.

The very high acquisition rate of TLS is generally exploited to perform mobile mapping; for this aim, the laser scanner is mounted on a vehicle.

One can conceive, however, of using this instrument in a reverse way: a fixed instrument can be used to survey a mobile object. For In particular, the deflections of the elements of a bridge could be dynamically measured in near real time.

The structure of the paper is the following:

After the description of the city of Cosenza and of the San Francesco bridge, the operations carried out for the surveying are reported. The procedure adopted to obtain the $3 \mathrm{D}$ model of the bridge and of its surrounding environment, is outlined, and the use of the instrument as line scanner to carry out the acquisitions during a load test is described.
The 3D model and the results obtained by dynamic acquisitions are then shown.

Finally, future developments of the research are described.

\section{THE SAN FRANCESCO BRIDGE}

Cosenza, the ancient capital of the Italic tribe of the Bruttii, lies on a some hills that was inhabited 3000 years ago. It is located at the confluence of Busento and Crati rivers. Many ruins of the roman age were found. During the last years of the roman Empire, in 410 a.D. , the town was besieged by Alaric, king of the Visigoths, but it escaped destruction due to the king's sudden death, probably caused by malaria.

During the centuries, several earthquackes (1638 - 1783) destroyed almost all the monuments and the greatest buildings, so the large part of the houses and monuments actually present were built during the XVI, XVII and XVIII centuries. After the second world war the new city of Cosenza was built in the plain zone.

The San Francesco bridge is positioned in the plain zone, near the confluence of Busento and Crati rivers, and it faces the hill of the older historical centre.

The works of Santiago Calatrava are often characterized by considerable complexity. They are often comparable to real sculptures, inserted in the surrounding environment. This is true, even more so, for its famous cable-stayed bridges.

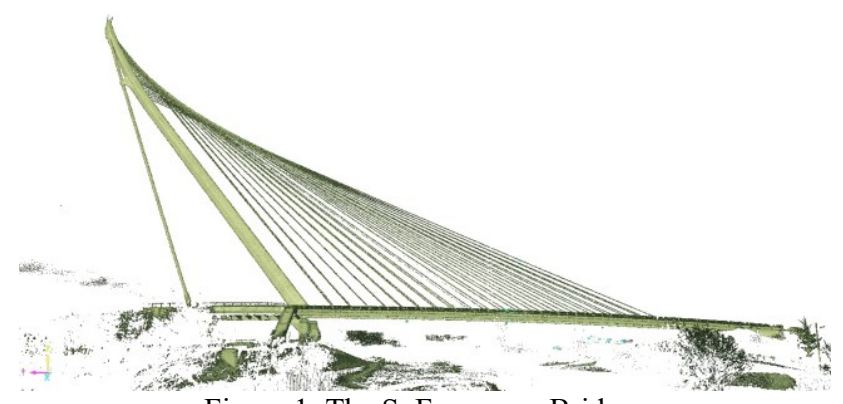

Figure 1. The S. Francesco Bridge.

The San Francesco Bridge (Figure 1) is a structure in Cosenza, which spans the river Crati, allowing access to the east side of the city. The bridge is of the cantilever spar cable-stayed bridge type and consists of a single pylon, 95 meters high, 
counterbalancing a $200 \mathrm{~m}$ span with twenty lengths of twin cables. The pull of the twenty twin cables is opposed by a pair of large rods. The peculiarity of the work is given by the upper anchors of the cables, which give the effect of a sail. The deck is a metal structure, resting on two end zones in reinforced concrete.

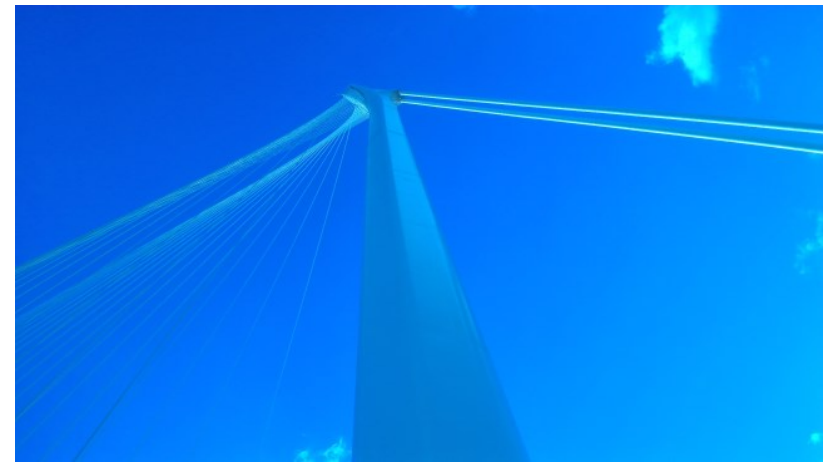

Figure 2. The pylon of the bridge and the cables.

\section{THE SURVEYING OPERATIONS}

\subsection{The static survey}

All of the bridges by Calatrava were designed with reference to the environment in which they are located; thus we cannot effectively represent it if they are removed from their territorial context.

The first laser scanner surveying was carried out for the purpose of representation, and concerned the bridge, the support areas and the surrounding urban area, as well as a stretch of the river Crati and the hill of the historic centre.

The laser scanner RIEGL VZ 1000 was used, which offers the following characteristics:

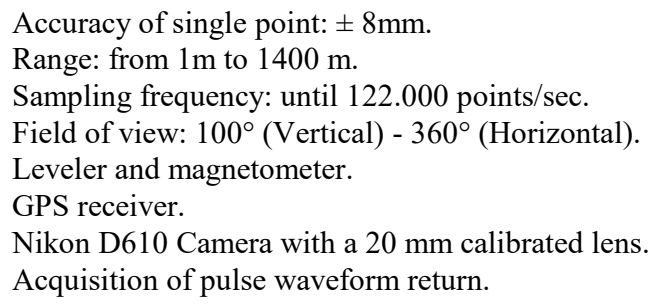

This last characteristic allows us to discriminate the terrain or an object from the vegetation that covers it.

Due to the complexity of the bridge, 14 scan stations were chosen and 37 point clouds were acquired.

In particular: (a) 13 scans were acquired from the area to the west and on the bridge deck; (b) two scans were carried out from a station positioned on a bridge at the south side (Europa bridge), (c) three scans from the north-east, (d) five scans from the south-east, (e) seven scans were taken from the left bank of the river, (f) seven scans under the deck. Other scans have been acquired for the details.

The processing of data from the laser scanner was performed with the RiscanPro ${ }^{\circledR}$ and Geomagic ${ }^{\circledR}$ software.

In the following, we can see the 3D model of the bridge and of the surrounding zone.

Figure 3 shows a view of the 3D model from the South-East with the new zone of the city. In figure 4 , the model is seen from the opposite line of sight; the riverbed of the Crati river is visible.

The basis of the bridge pylon is represented in figure 5; the stairs leading to the bank of the river take on the appearance of legs. This effect is even more evident in Figure 6, which shows the intrados of the bridge metal deck. We also see the double bundle of cables that gives the appearance of a sail to the bridge.

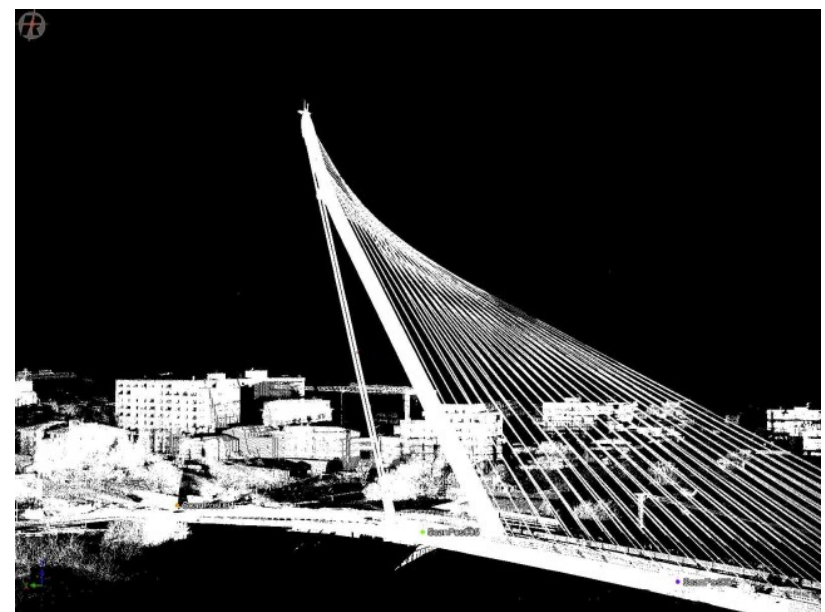

Figure 3. View of the 3D model from the South-East.

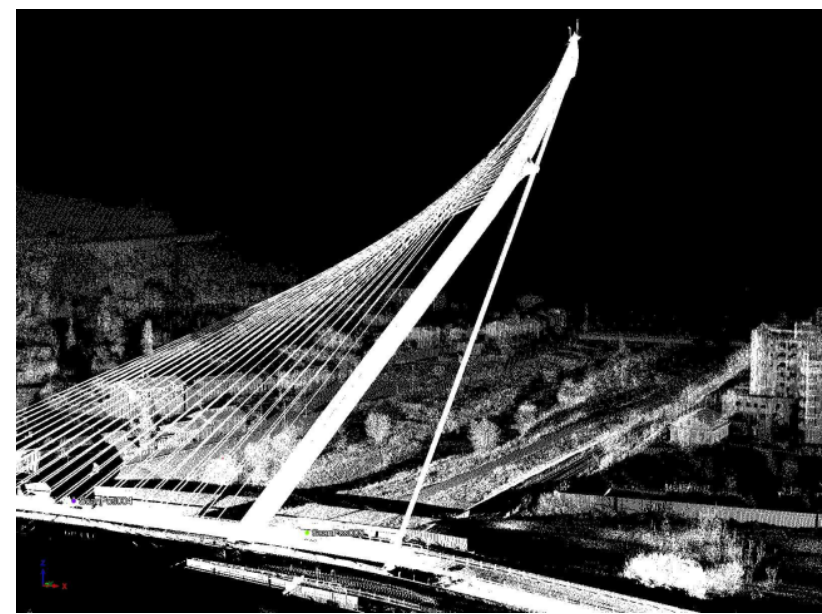

Figure 4. View of the 3D model from the North-West.

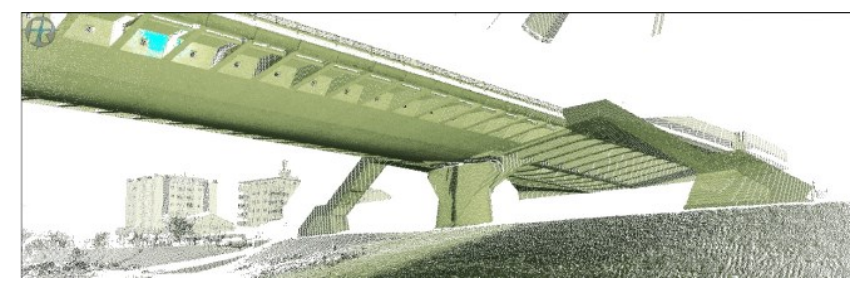

Figure 5. The basis of the pylon.

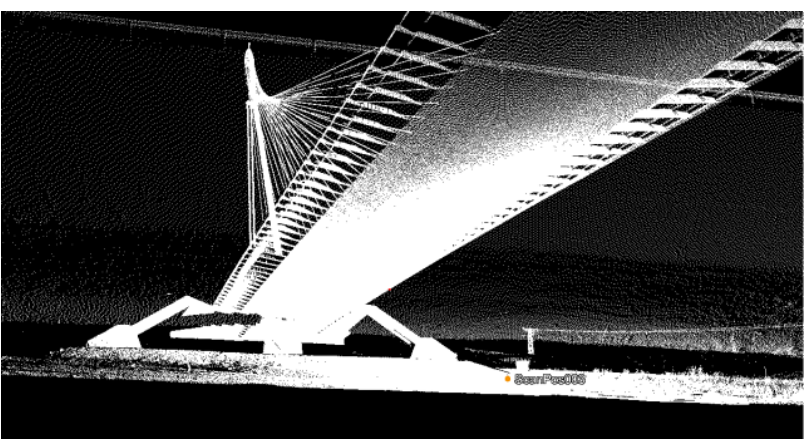

Figure 6 . The intrados of the bridge. 


\subsection{The dynamic survey}

The second survey was made using the laser scanner in line scanner mode.

The very high acquisition rate of TLS is generally exploited to perform mobile mapping; for this aim, the laser scanner is mounted on a vehicle: a mobile instrument is used to map a static object (land). One can think, however, of using this instrument in a reverse way: a fixed instrument can be used to survey a mobile object. In particular, the deflections of the superstructure of a bridge could be dynamically measured in near real time.

The method consists of placing a laser scanner, set up as linescanner, under the superstructure of a bridge and acquiring continuously a line parallel to the axis of the deck.

The displacements with respect to the line surveyed under static conditions and without loads, allow us to obtain the elastic line. It is possible, in this way, to extract an elastic line for each scanned line; that is, up to several dozens of lines per second. The timestamp of each point acquired by the laser scanner could be used in the line-scanner configuration, in order to align the scans to the position of the mobile loads, obtained by GNSS receivers.

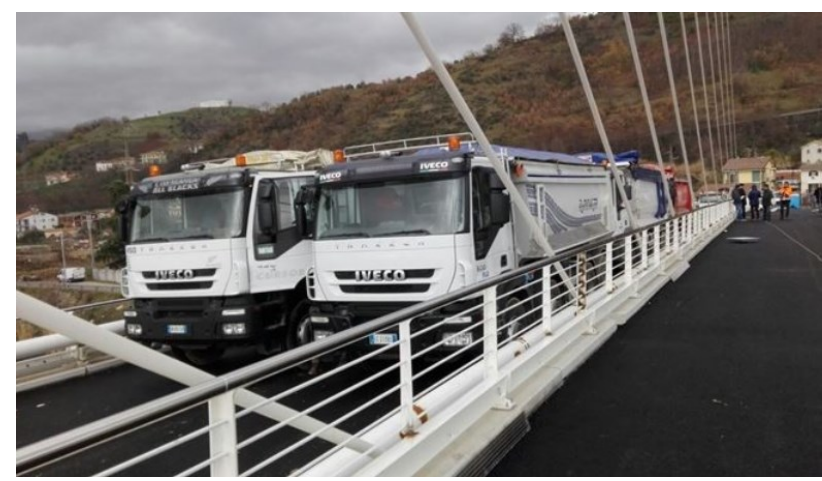

Figure 7. Six of the trucks used for the loading test.

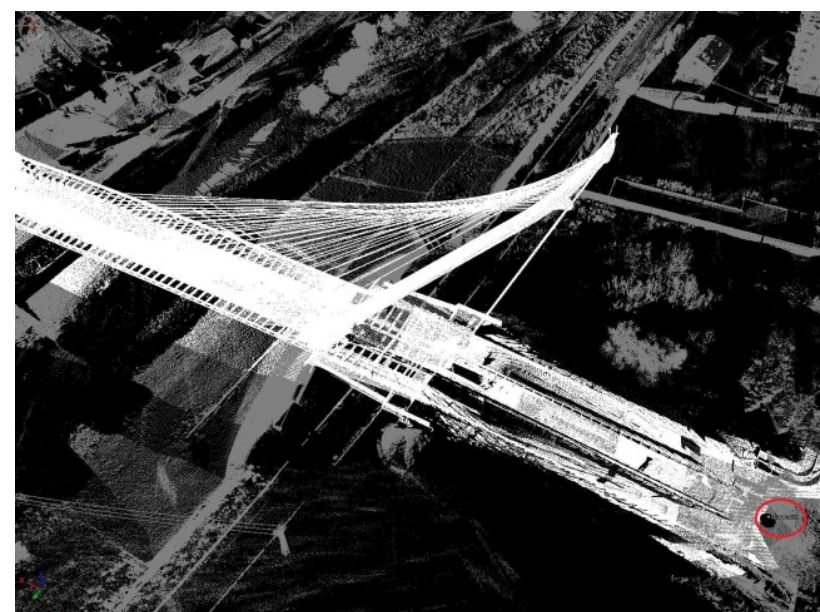

Figure 8. Aerial view with the TLS station point used for the dynamic acquisition (circled in red)

The experiment has been carried out during a load test; the mobile loads were obtained by positioning up to ten heavy trucks on the deck (Figure 7).

For the official test, a total station and an electronic level have been used. Furthermore, some strain sensors were positioned on the deck and on the pylon. Inclination sensors, connected wirelessly, gave the instantaneous inclination along the pylon.
The VZ100 laser scanner was positioned along the longitudinal axis of the bridge, at a $90 \mathrm{~m}$ distance from the basis of the rods that counterbalance the cables, in a stable zone. From this position, the vertical plane described by the laser beam intersects the external part of the pylon, characterized by an elliptic section; only a short zone is hidden by the rods. Thus, it is possible to obtain the shape of the pylon and its instantaneous elastic lines during the transit of mobile loads.

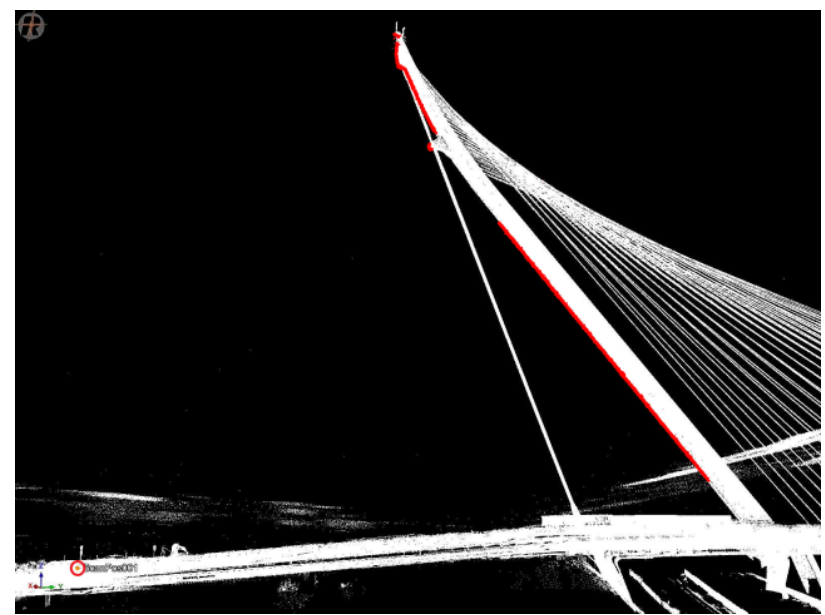

Figure 9. The track of the line scanner on the model. The station point is red.

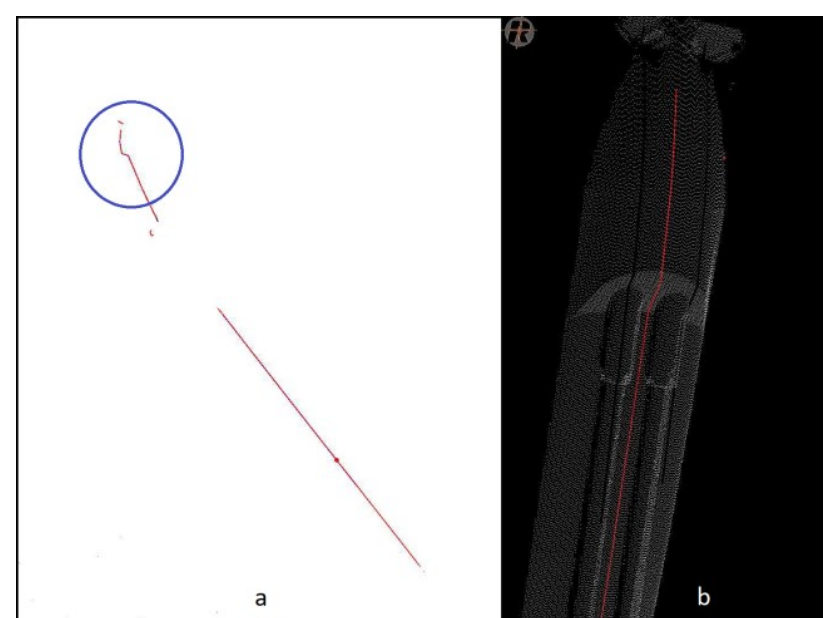

Figure 10. The track of a single scan: a) whole line; $b$ ) enlargement superimposed on the upper part of the pylon.

The layout of the test can be seen in figure 9. The station is on the left, circled in red; the red line is the track of the laser beam. A section obtained with a single vertical scan is reported in figure 10a; the upper part of the line, circled in blue, is superimposed on the point cloud of the terminal zone of the pylon in figure $10 \mathrm{~b}$.

The acquisitions have been carried out in three conditions: a) with unloading bridge, b) during the stop of the first two trucks, c) during the run and the stop of the second couple of trucks. The results of the line scanner acquisitions has been compared to the inclination sensors ones and to the outcomes of the total station. The comparison confirmed the reliability of the methodology.

Some results of the test are shown in figures 11 to 13 , where the position of enlarged cloud point is circled on the top right thumbnail of the bridge. The blue points have been acquired with unloading bridge. 
First of all, we can observe that the thickness of the blue point cloud is about $8 \mathrm{~mm}$, so we can assume a precision of about 4 $\mathrm{mm}$. This precision is sufficient, given the order of magnitude of the displacements to be measured.

Figure 11 shows the displacements obtained for the upper zone of the pylon, at a height of $81 \mathrm{~m}$ above the station point. The left dense point cloud in red has been obtained during the stop of the first two trucks. Also in this case the thickness is about 8 $\mathrm{mm}$. The right red dense point cloud has been obtained during the stop of the second couple of trucks. Altogether there were four trucks on the deck. Also in this case the thickness is about $8 \mathrm{~mm}$.

The sparse red point cloud has been obtained during the running of the last two trucks. A densification is visible in coincidence with a slowdown. The total displacement is $68 \mathrm{~mm}$, while the displacement induced by the first two trucks is about one half. Qualitatively similar results are shown in the next figures.

Figure 12 shows the point clouds obtained in the anchorage zone of the rods, at a height of $69 \mathrm{~m}$ above the station point. In this case, we can observe a sort of adjustment of the rods after applying the load due to the second pair of trucks. The maximum displacements are comparable to those of the upper part; this is reasonable, given the small distance.

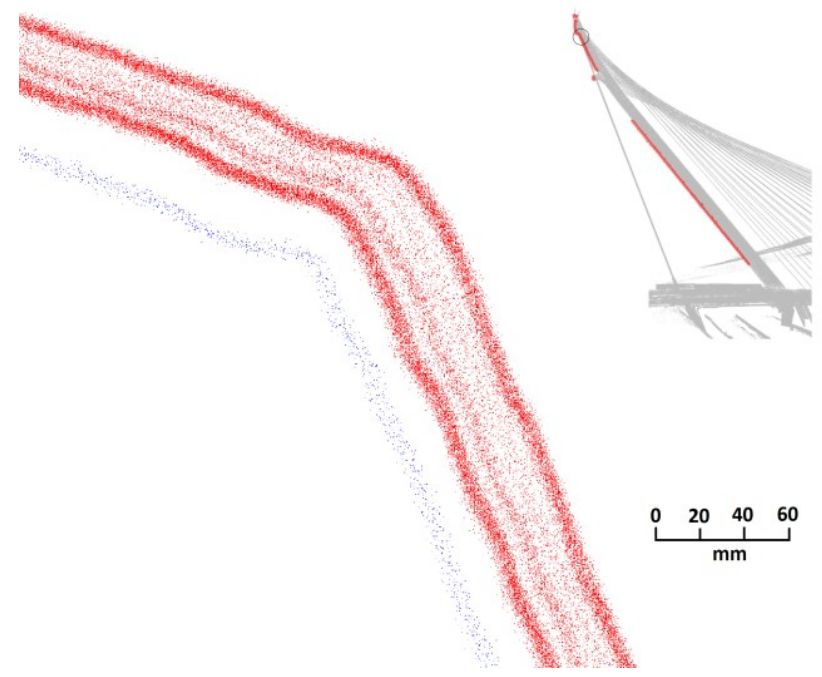

Figure 11. Enlargement of the line scanner point cloud acquired during the load test at the upper part of the pylon.

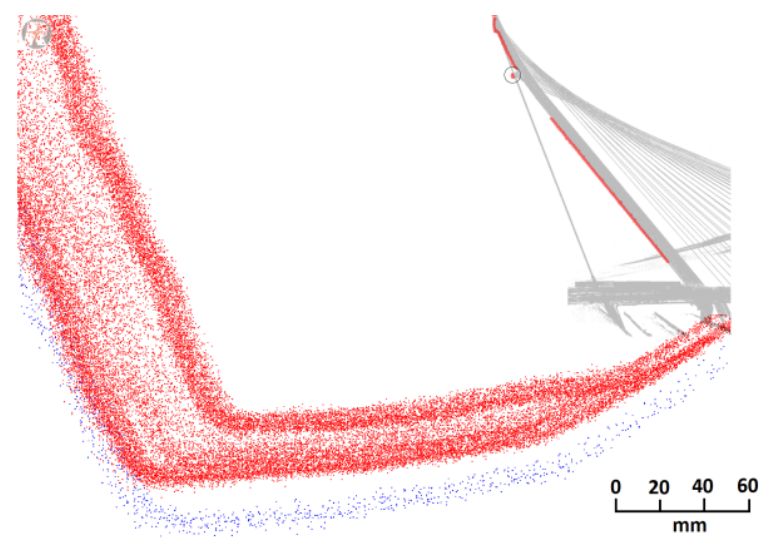

Figure 12. Enlargement of the line scanner point cloud acquired during the load test at the middle part of the pylon.

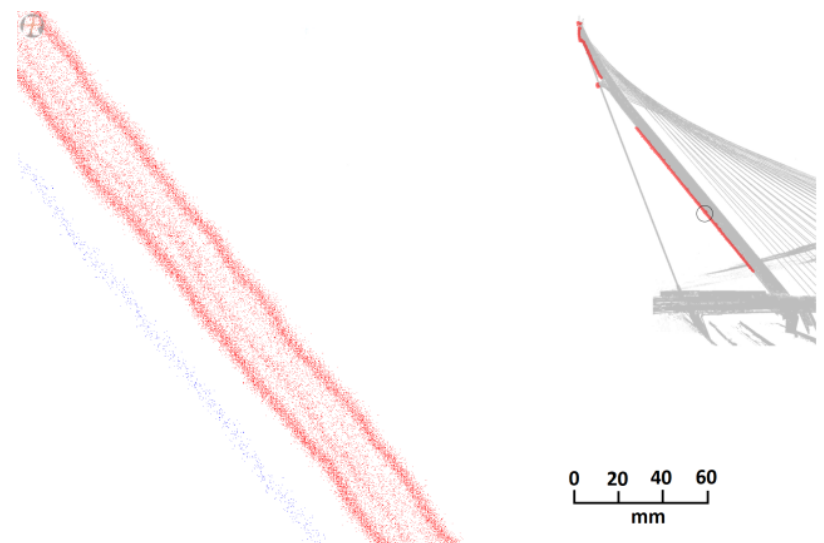

Figure 13. Enlargement of the line scanner point cloud acquired during the load test at the lower part of the pylon.

Figure 13 shows the point clouds obtained in the lower zone of the pylon, at a height of $39 \mathrm{~m}$ above the station point. In this case. The maximum displacements are $53 \mathrm{~mm}$.

\section{CONCLUSIONS}

In this paper the survey of the San Francesco bridge by Santiago Calatrava in Cosenza, Italy, has been described.

The 3D model of the bridge and of the surrounding environment has been obtained.

An application of the TLS, used as line scanner, has been performed during a load test. The deformation of the pylon has been obtained before, during and after the charge phase. The results are in agreement with those obtained with classical techniques.

In the future, the problems connected to the synchronization of the laser scanner and of the instruments used to detect the position of the moving loads will be deeply analyzed.

Another research will regard a comparison with the results obtained by using GB SAR (Ground-Based Synthetic Aperture Radar), used to measure the vibration frequencies and the displacements.

\section{REFERENCES}

Artese, G., De Napoli, L., \& Artese, S., 2013a. TOF laser scanner for the surveying of statues: a test on a real case. In: The International Archives of the Photogrammetry, Remote Sensing and Spatial Information Sciences, 5, W2. pp. 67-72 DOI: 10.5194/isprsarchives-XL-5-W2-67-2013.

Artese, S., 2014. The city model as a tool for participatory urban planning - A case study: The Bilotti Open Air Museum of Cosenza. ISPRS Annals of the Photogrammetry, Remote Sensing and Spatial Information Sciences, Volume 2, Issue 5, pp 25-32.

Artese, G., Perrelli, M., Artese, S., Meduri, S., \& Brogno, N., 2015. POIS, a low cost tilt and position sensor: design and first tests. Sensors, 15(5), pp. 10806-10824.

Artese, G., Perrelli, M., Artese, S., Manieri, F., 2015b. Geomatics activities for monitoring the large landslide of Maierato, Italy. Applied Geomatics, 7(3), pp. 171-188. 
Artese S, Lerma J L, Zagari G, Zinno R (2016a). The survey, the representation and the structural modeling of a dated bridge - Proceedings of the 8th International Congress on Archaeology, Computer Graphics, Cultural Heritage and Innovation 'ARQUEOLÓGICA 2.0', Valencia (Spain), Sept. 5 $-7,2016$ pp. 162-168.

Artese, G., Fiaschi, S., Di Martire, D., Tessitore, S., Fabris, M., Achilli, V., Ahmed, A., Borgstrom, S., Calcaterra, D., Ramondini, M., Artese, S., Floris, M., Menin, A., Monego, M., Siniscalchi, V. 2016b. Monitoring of land subsidence in ravenna municipality using integrated SAR - GPS techniques: Description and first results. International Archives of the Photogrammetry, Remote Sensing and Spatial Information Sciences - ISPRS Archives, Volume 41, 2016, Pages 23-28.

Artese, S., Achilli, V., \& Zinno, R., 2018. Monitoring of Bridges by a Laser Pointer: Dynamic Measurement of Support Rotations and Elastic Line Displacements: Methodology and First Test. Sensors, 18(2), 338.

Ĉapo, A., Babiü, L., Pribipeviü, B., 2011. Application of a 3D terrestrial laser scanner in a survey of a railway bridge" Sava Jakuševac". In 5th International Conference on Engineering Surveying, pp 71-76.

Deruyter, G., Hennau, M., De Wolf, V., Dewulf, N., 2009. Approach for comparing design and as built models based on data acquisition using a 3D terrestrial laser scanner, a case study. In 4th International workshop on $3 D$ Geo-information, pp. 101-116.

Lerma, J.L., Van Genechten, B., Heine, E., Santana, M., 2008. Theory and practice on Terrestrial Laser Scanning. Editorial de la Universidad Politécnica de Valencia, Valencia.

Tang, P., Akinci, B., 2012. Automatic execution of workflows on laser-scanned data for extracting bridge surveying goals. Advanced Engineering Informatics, 26(4), 889-903.

Zinno, R., Artese, S., Clausi, G., Magarò, F., Meduri, S., Miceli, A., \& Venneri, A., 2019. Structural Health Monitoring (SHM). The Internet of Things for Smart Urban Ecosystems. Springer, Cham, pp. 225-249. 